University of Nebraska - Lincoln

DigitalCommons@University of Nebraska - Lincoln

Drought Mitigation Center Faculty Publications Drought -- National Drought Mitigation Center

1979

\title{
Turbulence Spectra above a Vegetated Surface under Conditions of Sensible Heat Advection
}

\author{
Raymond P. Motha \\ University of Missouri \\ Shashi B. Verma \\ University of Nebraska - Lincoln \\ Norman J. Rosenberg \\ University of Nebraska - Lincoln
}

Follow this and additional works at: https://digitalcommons.unl.edu/droughtfacpub

Part of the Climate Commons, Environmental Indicators and Impact Assessment Commons, Environmental Monitoring Commons, Hydrology Commons, Other Earth Sciences Commons, and the Water Resource Management Commons

Motha, Raymond P.; Verma, Shashi B.; and Rosenberg, Norman J., "Turbulence Spectra above a Vegetated Surface under Conditions of Sensible Heat Advection" (1979). Drought Mitigation Center Faculty Publications. 162.

https://digitalcommons.unl.edu/droughtfacpub/162

This Article is brought to you for free and open access by the Drought -- National Drought Mitigation Center at DigitalCommons@University of Nebraska - Lincoln. It has been accepted for inclusion in Drought Mitigation Center Faculty Publications by an authorized administrator of DigitalCommons@University of Nebraska - Lincoln. 


\title{
Turbulence Spectra above a Vegetated Surface under Conditions of Sensible Heat Advection ${ }^{1}$
}

\author{
Raymond P. Motha, ${ }^{2}$ Shashi B. Verma and Norman J. Rosenberg \\ Center for Agricultural Meteorology and Climatology, Department of Agricultural Engineering and \\ Natural Resources, University of Nebraska, Lincoln 68583
}

(Manuscript received 9 June 1978, in final form 14 November 1978)

\begin{abstract}
Spectra of vertical and horizontal velocity, air temperature and humidity fluctuations were analyzed from measurements made over a well-watered alfalfa crop under conditions of sensible heat advection. Vertical velocity and air temperature spectra as well as cospectra of momentum, sensible heat and water vapor were found to be dependent on atmospheric thermal stratification. These spectra and cospectra were shifted toward higher frequencies under advective as compared to lapse conditions. These results indicate that the predominant eddy sizes are relatively smaller under advective conditions. Humidity spectra, on the other hand, were independent of daytime thermal stratification conditions but were influenced by conditions of the crop. The humidity spectra over a transpiring crop were shifted toward lower frequencies as compared to those over a less well-developed crop canopy.
\end{abstract}

\section{Introduction}

Spectral analysis is used to examine the contributions of different frequencies of turbulent fluctuations to the total variance of such entities as wind velocity, temperature and humidity. Mathematically,

$$
\int_{n l}^{n_{l l}} S_{x}(n) d n=\overline{x^{\prime 2}},
$$

where $S_{x}(n)$ is the spectrum of some property $x^{\prime}$ (e.g., fluctuations of vertical or horizontal velocity, air temperature or humidity) and $n$ is the frequency $(\mathrm{Hz})$. The lower and upper limits of integration $\left(n_{l}\right.$ and $n_{u}$, respectively) include all frequencies that contribute to the total variance, and are designed to eliminate possible influence from trends and long-term oscillations in the observed time series. The prime symbol denotes instantaneous departures from the mean and the overbar denotes a time average. Vertical fluxes of momentum, sensible heat and moisture can also be evaluated by means of spectral analysis by

$$
\int_{n l}^{n_{u}} C_{u w}(n) d n=\overline{u^{\prime} w^{\prime}}
$$

\footnotetext{
1 Published as Paper No. 5550, Journal Series, Nebraska Agricultural Experiment Station. The work reported was conducted under Regional Research Project 11-33 and Nebraska Agricultural Experiment Station Project 11-49.

2 Present affiliation: University of Missouri, Atmospheric Science Department, in cooperation with the Center for Environmental Assessment Services, Columbia, MO. 65201.
}

$$
\begin{aligned}
& \int_{n_{l}}^{n_{u}} C_{w \theta}(n) d n=\overline{w^{\prime} \theta^{\prime}} \\
& \int_{n_{l}}^{n_{u}} C_{w q}(n) d n=\overline{w^{\prime} q^{\prime}},
\end{aligned}
$$

where $C_{u w}(n), \mathrm{C}_{w \theta}(n)$ and $C_{w q}(n)$ are cospectra representing the transfer of momentum, sensible heat and moisture, respectively. A comparison of spectra and cospectra of data measured under different atmospheric conditions should allow identification of distinguishing characteristics of the structure of turbulence.

Several investigators (e.g., Priestley, 1959; Haugen et al., 1971) have presented records of vertical velocity fluctuations under lapse and nocturnal inversion conditions. Under lapse conditions, small and relatively rapid irregular fluctuations appear to be imposed on larger and much slower irregular fluctuations. The smaller fluctuations (associated with high frequencies) are primarily due to mechanical turbulence which results from the interaction of turbulent stresses with mean wind shear. The larger fluctuations (associated with low frequencies) are the result of thermal turbulence arising from the interaction of the vertical velocity and buoyancy fluctuations. Wyngaard (1973) showed that under lapse conditions the mechanical (or shear) production decreases in importance due to the increasing effect of buoyancy on turbulent mixing. Priestley (1959) noted that under nocturnal inversion conditions, only the small, rapid fluctuations were present.

Sensible heat advection occurs during much of the growing season in the central Great Plains. Evapotrans- 
TABLE 1. Mean wind speed at $4 \mathrm{~m}$ and air temperature and vapor pressure at $4.4 \mathrm{~m}$ on days selected for spectral analysis. (Information on plant height and leaf area index is also included.)

\begin{tabular}{|c|c|c|c|c|c|c|c|c|c|}
\hline Run & Date & $\begin{array}{l}\text { Time } \\
\text { (solar) }\end{array}$ & $z / L$ & $\begin{array}{c}\text { Thermal } \\
\text { stratification }\end{array}$ & $\begin{array}{l}\text { Wind speed } \\
\left(\mathrm{m} \mathrm{s}^{-1}\right)\end{array}$ & $\begin{array}{l}\text { Temperature } \\
\left({ }^{\circ} \mathrm{C}\right)\end{array}$ & $\begin{array}{l}\text { Vapor } \\
\text { pressure } \\
(\mathrm{mb})\end{array}$ & $\begin{array}{l}\text { Crop con } \\
\text { Plant } \\
\text { height } \\
\text { (m) }\end{array}$ & lition \\
\hline $14 \mathrm{~A}$ & 0710 & $1251-1345$ & -0.16 & Lapse & 6.58 & 30.5 & 22.8 & 0.15 & 1.0 \\
\hline $14 \mathrm{~B}$ & 0710 & $1351-1440$ & -0.22 & Lapse & 7.09 & 31.2 & 23.2 & 0.15 & 1.0 \\
\hline $26 \mathrm{~B}$ & 0718 & $1151-1245$ & +0.03 & Advective & 7.03 & 34.7 & 24.1 & 0.45 & 2.5 \\
\hline $26 \mathrm{C}$ & 0718 & $1251-1335$ & +0.03 & Advective & 7.12 & 35.1 & 25.2 & 0.45 & 2.5 \\
\hline $31 \mathrm{~A}$ & 0719 & $1351-1441$ & +0.03 & Advective & 7.74 & 34.8 & 19.7 & 0.45 & 2.5 \\
\hline $36 \mathrm{~B}$ & 0727 & 0951-1045 & -0.11 & Lapse & 4.73 & 24.2 & 15.1 & 0.60 & 5.0 \\
\hline
\end{tabular}

piration frequently consumes as much as twice the energy supplied by the net radiation under these conditions (Rosenberg, 1969; Rosenberg and Verma, 1978). The additional energy consumed in evapotranspiration is provided by the advection of sensible heat from arid regions which are primarily to the south and southwest. Daytime temperature inversions result under these conditions and the sensible heat flux is directed toward the crop. The inverted temperature profiles extend to at least 14-16 $\mathrm{m}$ above the ground indicating that advection is not a small-scale phenomena but is likely regional in character [For detailed discussion, see Brakke et al. (1978) and Rosenberg and Verma (1978).] In view of the large fluxes of sensible heat and water vapor which are known to occur, the nature of turbulent transport under advective temperature inversions appears to be different from that which occurs under nocturnal (or radiation) inversion conditions (Rosenberg, 1969; Rosenberg and Verma, 1978; Motha et al., 1978).

In this paper we examine the turbulence spectra of wind velocity, temperature and humidity fluctuations and cospectra of the fluxes of momentum, sensible heat and moisture which occur over a well-watered alfalfa crop under conditions of warm-air advection.

\section{Methods}

Turbulence measurements were made over an alfalfa field at the University of Nebraska Agricultural Meteorology Research Laboratory at Mead, Nebraska ( $41^{\circ}$ $09^{\prime} \mathrm{N} ; 96^{\circ} 30^{\prime} \mathrm{W}$; $354 \mathrm{~m} \mathrm{MSL}$ ) during June and July 1977. The alfalfa canopy was vigorously transpiring when measurements were made except for a short time after the crop was cut on 1 July 1977. Three-dimensional Gill (UVW) propeller anemometers ${ }^{3}$ were used for wind component measurements and fine-wire dry bulb and wet bulb thermocouples ${ }^{4}$ were used for air temperature and vapor pressure measurements. The sensors were mounted $4.45 \mathrm{~m}$ above the ground at the north end of an experimental alfalfa field approximately $400 \mathrm{~m}$ in the

\footnotetext{
${ }^{3}$ R. M. Young Co., Traverse City, Michigan (Model No. 27103).

4 Tillman, J. E. 1973. Wet and dry-bulb thermocouple psychrometry. Atmospheric Technology, National Center for Atmospheric Research, No. 2, p. 77.
}

north-south direction and $105 \mathrm{~m}$ in east-west direction. The field was surrounded, except on the north, by alfalfa of the same age and cultivar. Observations were made only when the wind direction ranged from southeast to southwest. A computer-controlled data acquisition system consisting of a mini-computer, analog to cligital converters and a magnetic tape drive was employed for sampling and recording all data. The turbulence signals were sampled 13 times per second. These signals were passed through a $5 \mathrm{~Hz} \mathrm{RC}$ low-pass filter.

Spectra and cospectra were computed using a fast Fourier transform technique on blocks of 4096 data points. The values resulting from each of seven to eight blocks of data were then averaged using the Bartlett averaging technique (Jenkins and Watts, 1968). The spectra and cospectra were normalized by multiplying the spectral and cospectral estimates by their respective frequencies and dividing by the total variance or covariance:

$$
\begin{aligned}
\text { normalized spectra } & =n S_{x}(n) / \overline{x^{\prime 2}} \\
\text { normalized cospectra } & =n C_{w x}(n) / \overline{w^{\prime} x^{\prime}} .
\end{aligned}
$$

A nondimensional frequency $(f)$ defined by

$$
f=\frac{n(z-d)}{\bar{u}}
$$

is used in our spectral plots (Silversides, 1974), where $\bar{u}$ is the mean wind speed at an above ground elevation and $d$ the zero plane displacement. From Taylor's hypothesis (see Pasquill, 1972), the wavelength $(\lambda)$ is related to $\bar{u}$ and the frequency $(n)$ by

$$
\lambda=\frac{\bar{u}}{n},
$$

where $\lambda$ is generally considered the scale representative of the size of atmospheric motions involved (McBean and Miyake, 1972) and is inversely proportional to the nondimensional frequency $f$ [Eqs. (7) and (8)].

The Gill UVW anemometer has errors due to inherent shortcomings in cosine response and frequency response (Horst, 1973). Below $0.3 \mathrm{~Hz}$ the major source of error 


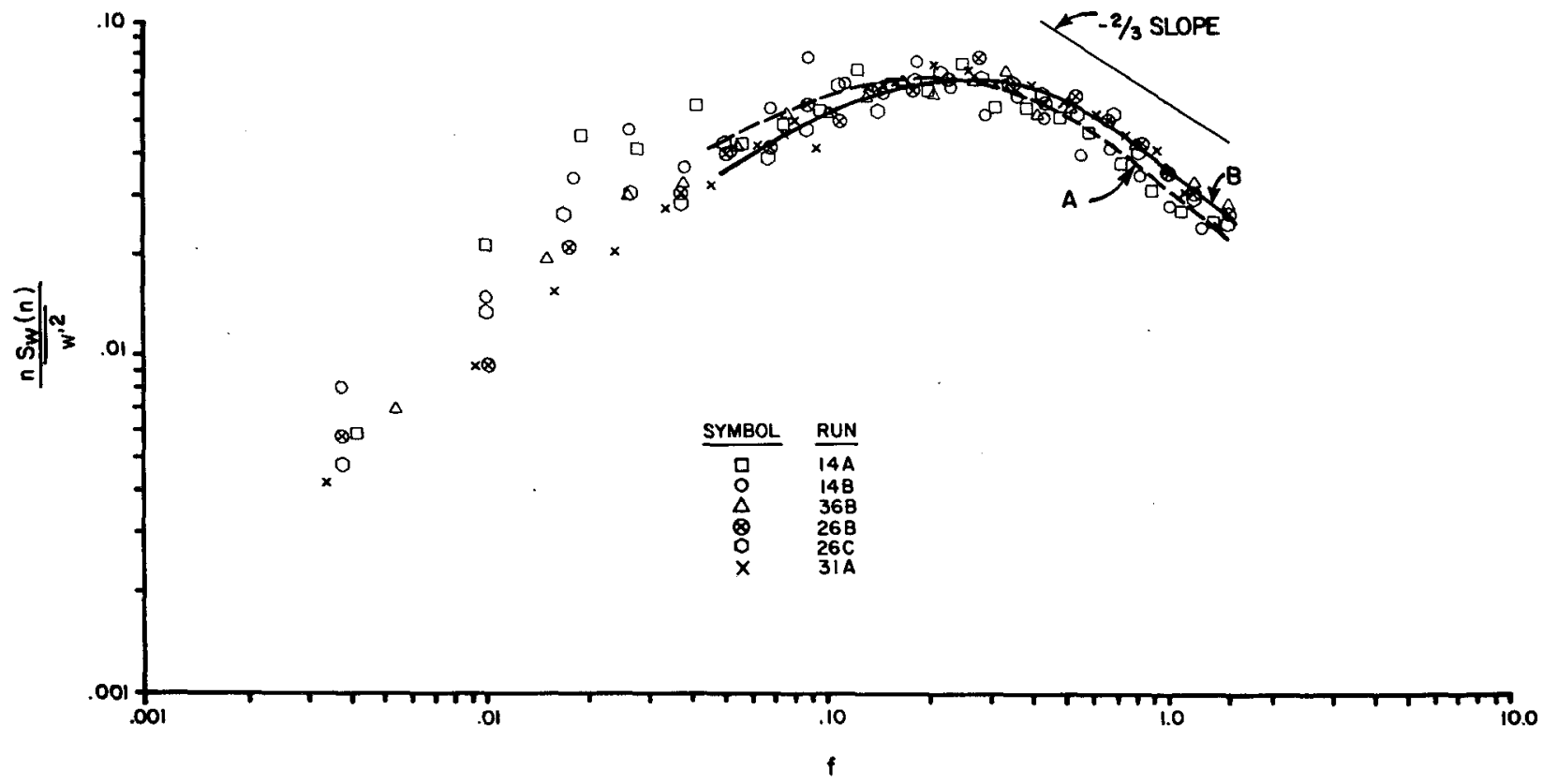

FIG. 1. Normalized logarithmic spectra of vertical velocity fluctuations for six runs-three under lapse and three under advective conditions. Dashed line (A) represents average curve for lapse conditions; solid line (B) represents average curve for advective conditions. Line with $-\frac{2}{3}$ slope in the inertial subrange is also shown.

is due to non-cosine response. For frequencies $>0.25 \mathrm{~Hz}$ the error due to high-frequency response limitations increases significantly. To correct the Gill anemometer data for its deviation from the perfect cosine response the propeller anemometers were first individually calibrated in a wind tunnel at the University of Iowa, Iowa City. The magnitudes of the three measured wind com- ponents $(u, v, w)$ were then determined by means of an iteration procedure described by Horst (1972) which corrects the data for non-cosine response.

The Gill anemometer data were corrected for frequency response, to a fair approximation, by treating the anemometer as a first-order system with a time constant $\tau=D / \bar{u}$ ( $D$ is a distance constant of the ane-

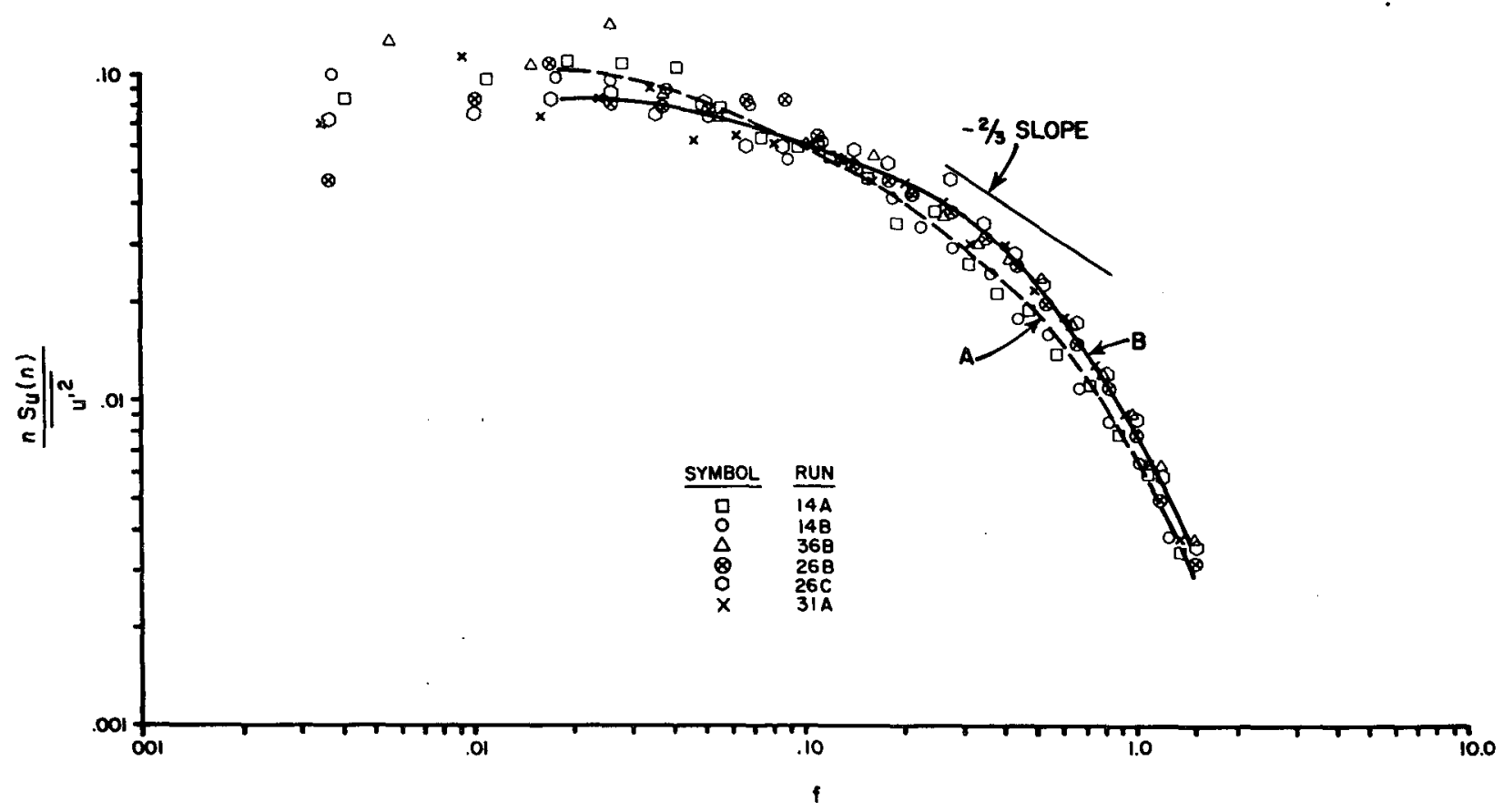

Fig. 2. As in Fig. 1 except for spectra of horizontal velocity fluctuations. 


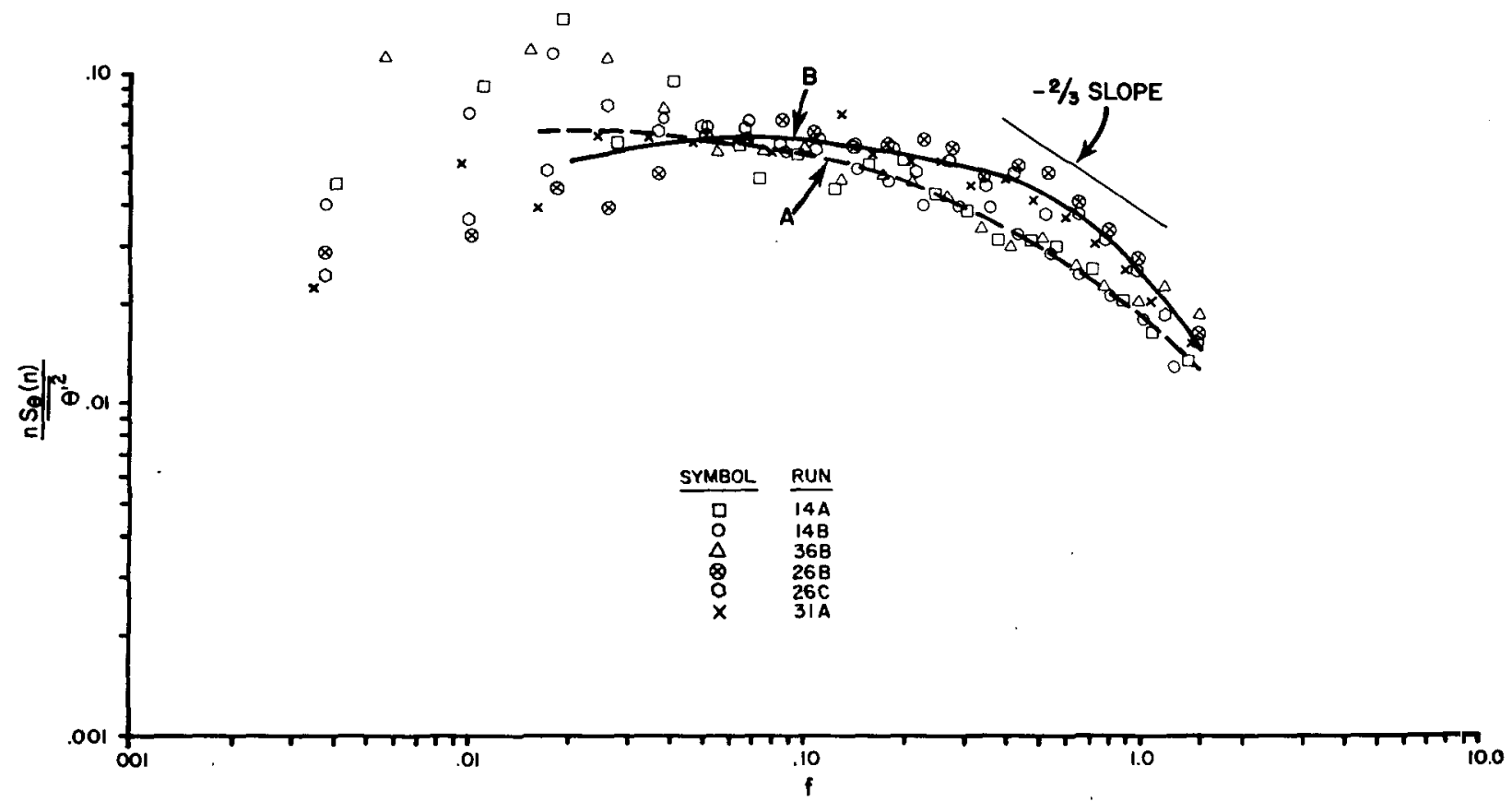

Fig. 3. As in Fig. 1 except for spectra of temperature fluctuations.

mometer which was determined from wind tunnel tests). lence. The primary emphasis of this paper, however; is Spectral estimates of the Gill anemometer were cor- a qualitative comparison of turbulence spectra over a rected for high-frequency response by a frequency-dependent factor $\left(1+4 \pi^{2} n^{2} D^{2} / \bar{u}^{2}\right)^{\frac{1}{2}}$ [for details, see Horst (1973)].

As stated above, we recognize the limitations of the Gill propeller anemometer for measurement of turbucrop surface under advective and nonadvective conditions. By mounting the propeller anemometers at 4.45 $\mathrm{m}$ above ground and by applying the corrections described above we believe we have minimized the loss in the flux carrying range.

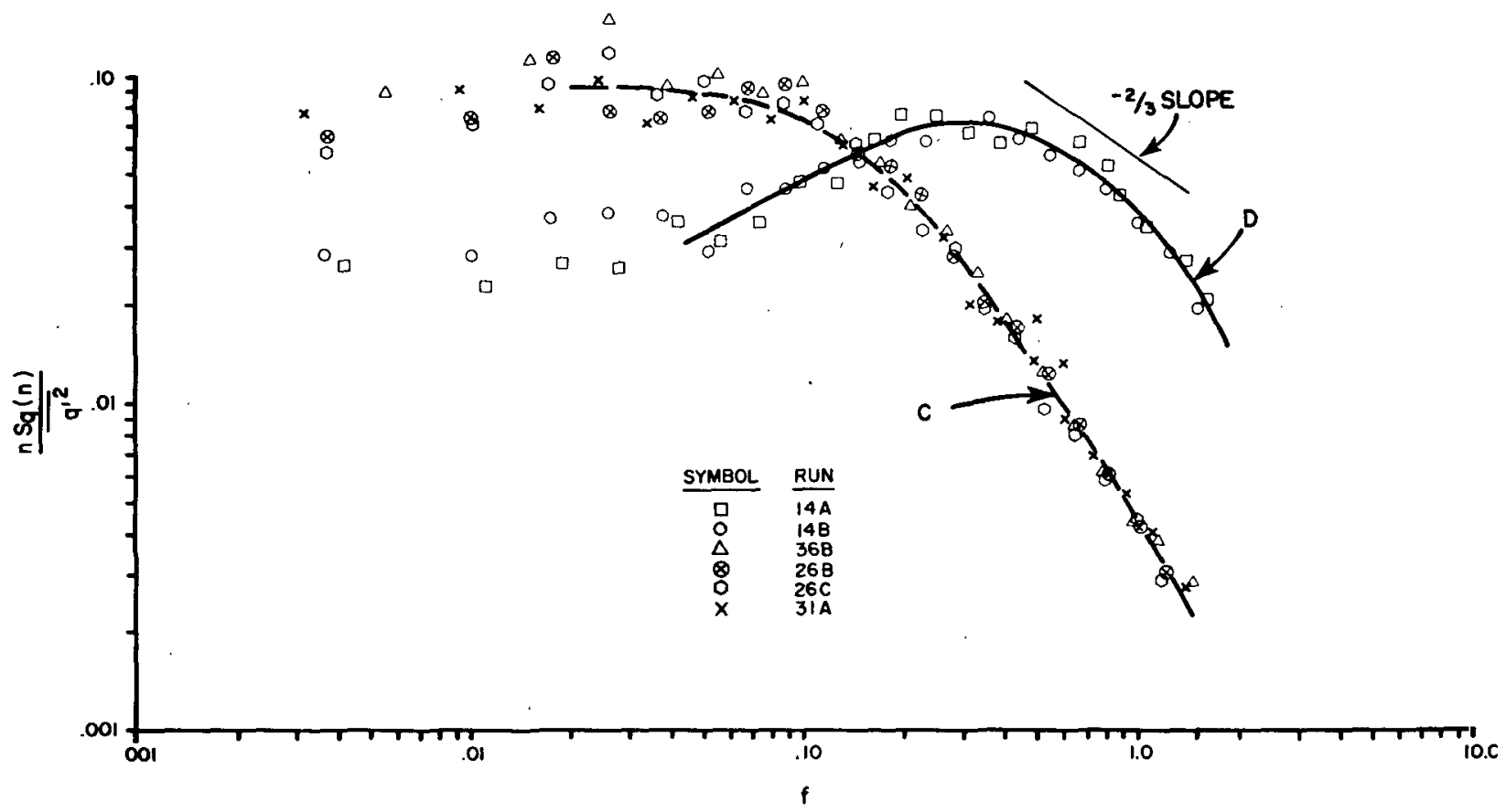

FIG. 4. As in Fig. 1 except for spectra of humidity fluctuations. Dashed line (C) is the average curve for full crop cover and solid line $(D)$ is the average curve for reduced crop cover. 


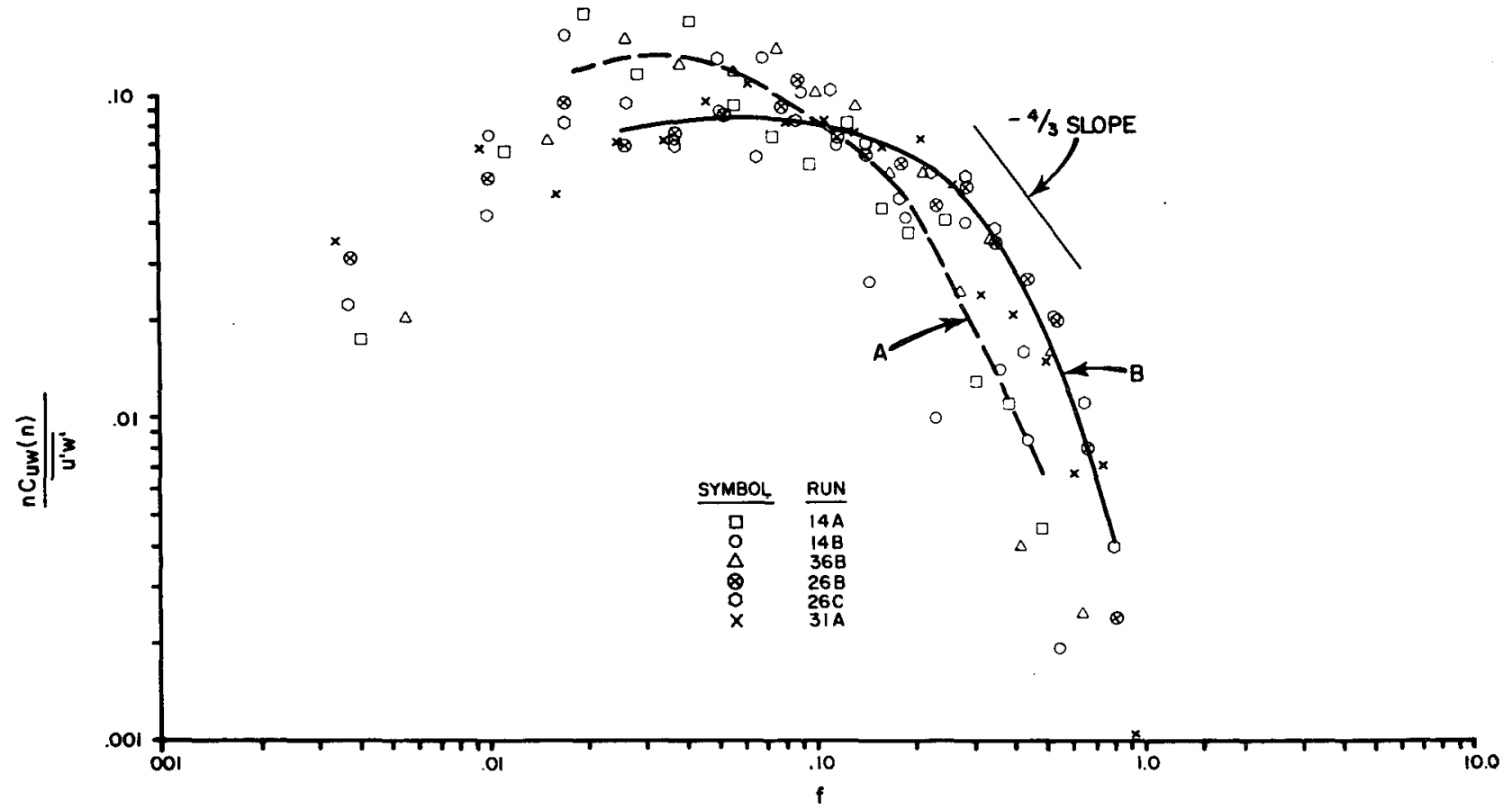

FIG. 5. Normalized logarithmic cospectra of vertical velocity and horizontal velocity fluctuations for conditions described in Fig. 1. Line with $-\frac{4}{3}$ slope in the inertial subrange is also shown.

\section{Results}

Spectral analysis was performed on the data obtained during four days of varying thermal stratification and crop conditions. Mean wind speed, temperature and vapor pressure are given in Table 1 for the days and time periods involved. Values of $z / L$, the moisture corrected Monin-Obukhov stability parameter (McBean, 1971; Motha et al., 1978)

are also included.

$$
\frac{z}{L}=-\frac{k z g \overline{w^{\prime} \theta^{\prime}}}{u_{*}^{3} \bar{\theta}_{v}}
$$

On 10 July (10 days after cutting), vegetative cover was developing. The leaf area index ${ }^{5}$ was about 1 and the crop height about $0.15 \mathrm{~m}$. Lapse conditions (negative $z / L$ ) prevailed on 10 July for the time periods of observation $^{6}$ (1251-1345, Run 14A; 1351-1440, Run 14B). Lapse conditions also prevailed on 27 July (0951-1045, Run 36B). There was a full canopy cover on 27 July (LAI $\approx 5.0$, crop height $\approx 0.60 \mathrm{~m}$ ). Daytime advectioninduced inversion conditions were observed on 18 July (1151-1245, Run 26B: 1251-1335, Run 26C) and 19 July (1351-1441, Run 31A). The crop was vigorously transpiring on these latter days (LAI $\approx 2.5$, crop height $\approx 0.45 \mathrm{~m}$ ). Latent heat fluxes averaged about $500 \mathrm{~W} \mathrm{~m}^{-2}$ around solar noon on 18 and 19 July compared to less than $100 \mathrm{~W} \mathrm{~m}^{-2}$ on 10 July. On 27 July the latent heat flux averaged about $300 \mathrm{~W} \mathrm{~m}^{-2}$ around solar noon.

${ }^{5}$ Leaf area index is the total area of leaf (one side) per unit area of soil beneath.

${ }^{6}$ All times are Central Standard.
The normalized logarithmic spectra of vertical and horizontal velocity components, temperature and humidity fluctuations for the six runs (including advective and nonadvective conditions) are presented in Figs. 1-4. The normalized logarithmic cospectra of momentum, sensible heat and humidity fluxes presented in Figs. 5-7. The smoothed curves, denoted by A and B in Figs. 1-3 and $5-7$, are derived from averages of the three runs each made under lapse and advective conditions, respectively. Smooth curves C and D in Fig. 4 represent a special case which will be explained below.

Peak frequencies shift toward higher values under advective compared to lapse conditions for the spectra of vertical velocity and temperature as well as for the cospectra of momentum, sensible heat and water vapor. The peak frequencies for the spectra of horizontal velocity were generally unaffected by daytime thermal stratification.

The logarithmic spectral peaks of vertical velocity spectra vary from approximately $f=0.15-0.25$ under lapse conditions to $f=0.25-0.29$ under advective conditions. Pasquill (1972) presents a collection of smoothed spectral curves for vertical velocity under lapse conditions which show a peak near $f=0.25$.

Our temperature spectra reach a peak at $f=0.02$ under lapse conditions and at $f=0.05-0.10$ under advective conditions. McBean (1971) found the spectral peak for temperature at approximately $f=0.02-0.03$ under lapse and near-neutral conditions.

For the cospectra of momentum, sensible heat and water vapor the peaks were at approximately $f=0.02$ 0.05 in lapse conditions and $f=0.06-0.10$ in advection 


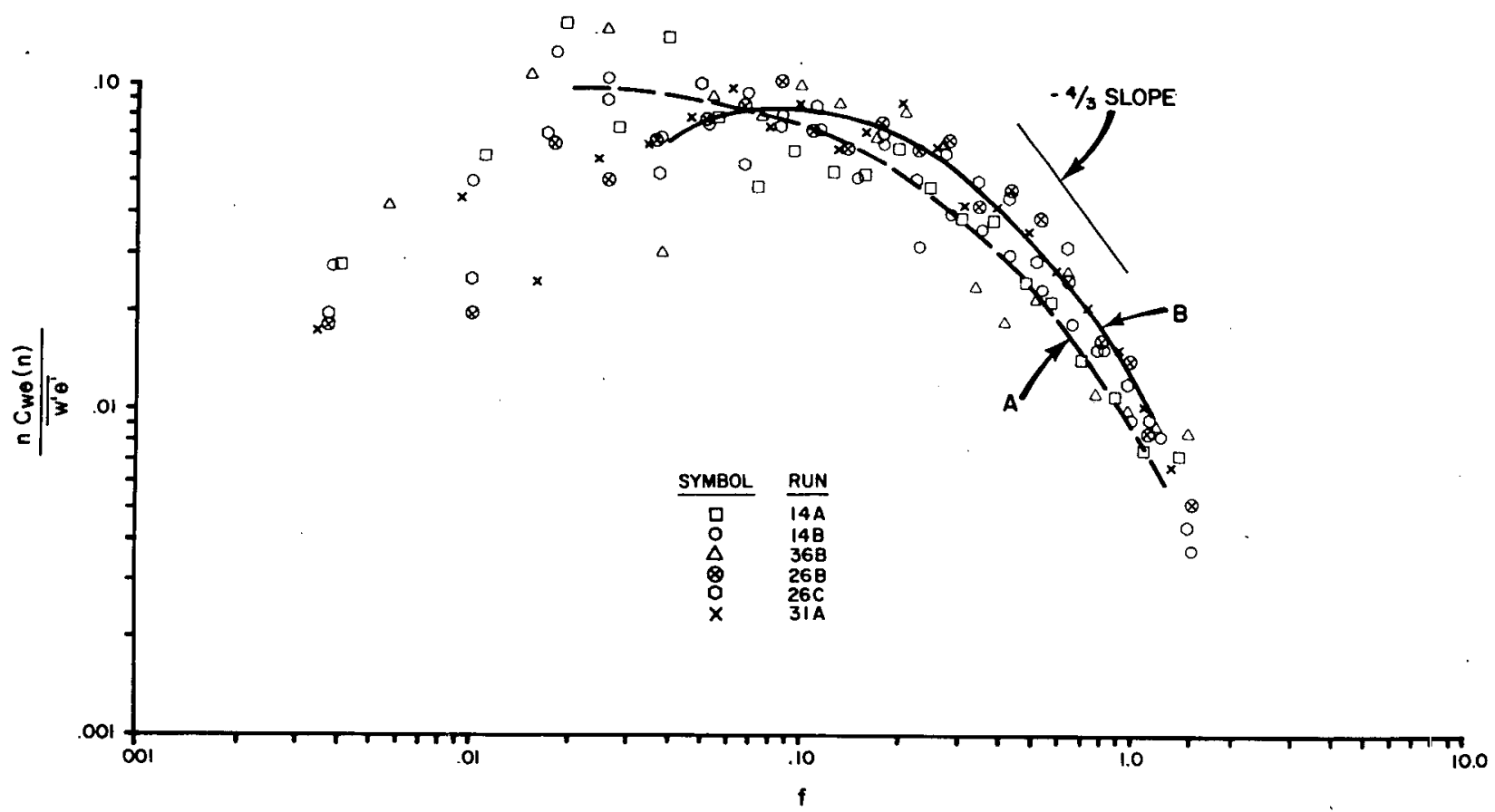

FIG. 6. Normalized logarithmic cospectra of vertical velocity and temperature fluctuations for conditions described in Fig. 5 .

conditions. Miyake and McBean (1970) found these cospectra peaks near $f=0.05$ for lapse conditions.

The humidity spectra are distinctly different from those of the other entities considered. The normalized logarithmic humidity $(q)$ spectra (Fig. 4) are separated into two distinct smooth curves, $\mathrm{C}$ and $\mathrm{D}$, neither of which is discernibly affected by thermal stratification. Curve $\mathrm{C}$ represents those runs made over transpiring crop (runs 26B, 26C, 31A and 36B) when LAI ranged from 2.5-5.0. Curve D represents runs made when the crop was short and not fully recovered from cutting (runs 14A and 14B, LAI $=1.0$ ). The spectral peaks occur near $f=0.32-0.36$ with the short crop cover and near $f=0.02-0.04$ with full crop cover.

\section{Discussion}

By examining the frequencies associated with the vertical velocity fluctuations a qualitative comparison

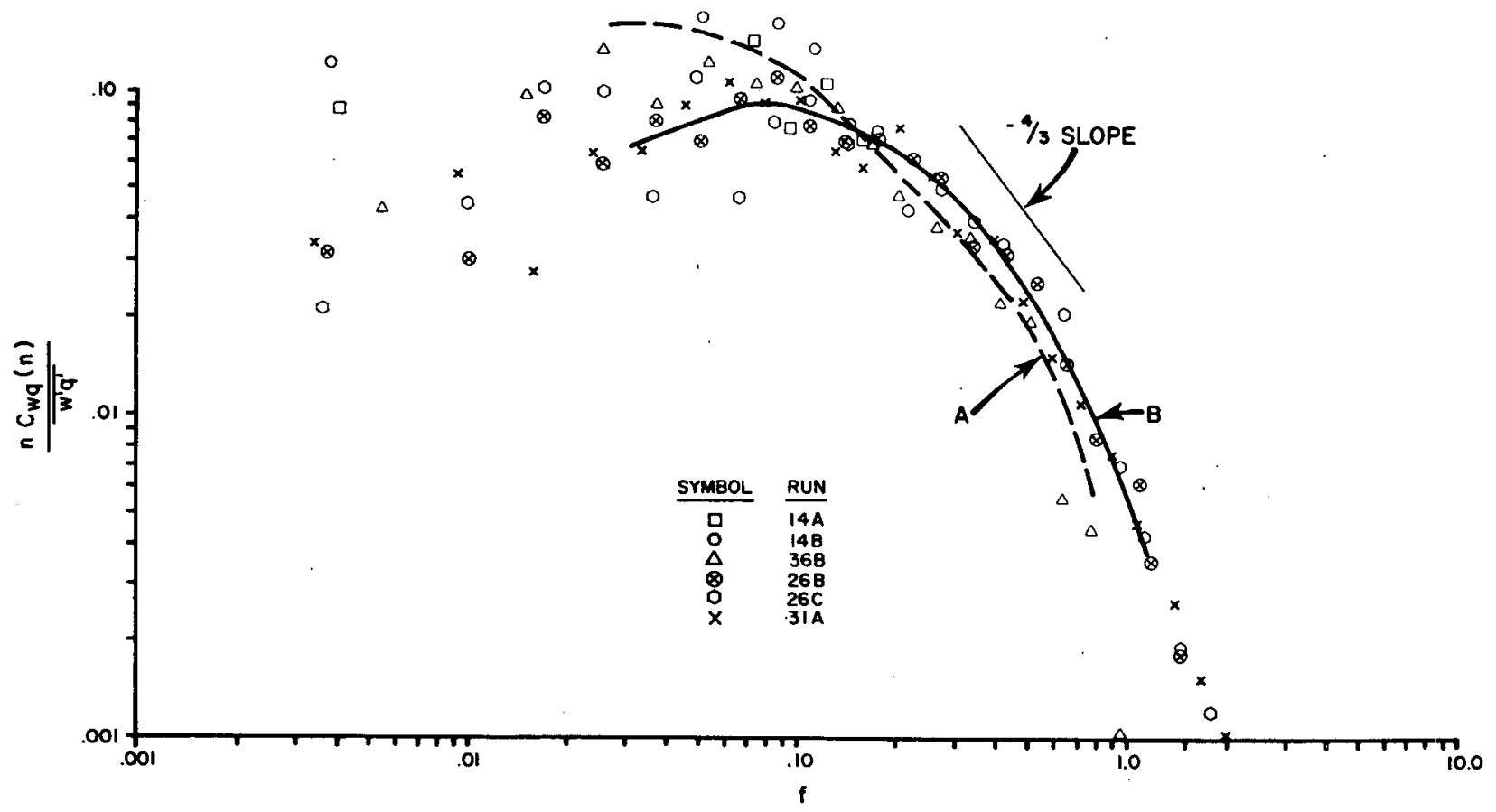

FIG. 7. Normalized logarithmic cospectra of vertical velocity and humidity fluctuations for conditions described in Fig. 5 . 
can be made of the predominant eddy sizes (or scales of fluctuations) contributing to the flux under varying atmospheric conditions. The spectral peaks were found at higher frequencies under advective than under lapse conditions. This shift indicates that the predominant eddy sizes associated with the vertical velocity fluctuations are relatively smaller under advective conditions.

Similar shifts toward higher frequencies in spectral and cospectral peaks were found in the temperature spectra as well as in the momentum, sensible heat and moisture cospectra under advective conditions. Thus, the smaller scale eddies, generally associated with the mechanical turbulence, appear to contribute more significantly to the flux under advective than under lapse conditions.

The spectra for humidity (Fig. 4) appear to depend on the degree of crop-canopy development. The humidity spectra over a transpiring crop shifted toward lower frequencies (or larger scales of fluctuation) as compared to those over a less well-developed canopy.

An explanation for the differences in spectra of vertical velocity, temperature, horizontal velocity and humidity can be summarized as follows: the vertical velocity and temperature fluctuations are influenced primarily by atmospheric conditions which determine the thermal stratification. Horizontal velocity fluctuations, however, are governed by mesoscale features in the atmosphere (e.g., Kaimal et al., 1972). Humidity fluctuations are affected by varying evapotranspiration rates which are dependent upon the condition of the underlying crop. These results appear to indicate that larger scale fluctuations are relatively more effective in carrying vapor produced by evapotranspiration. The shift in humidity spectra to lower frequencies suggests that a well-developed transpiring crop canopy acts as a local generator of humidity fluctuations which augments the larger scales of turbulent fluctuations.

\section{Summary and conclusions}

The spectra of vertical velocity and air temperature as well as cospectra of momentum, sensible heat and moisture shift, under advective conditions, toward higher frequencies than are found under lapse conditions. These results imply that smaller scale fluctuations dominate the transport processes under conditions of sensible heat advection. However, humidity spectra seem to be influenced by the stage of crop development and/or by the intensity of the transpiration process. Larger scale humidity fluctuations were found over a transpiring crop (LAI > 2.0) as compared to those measured over a crop of limited leaf area.

Propeller anemometers were used to measure the three wind components. The errors due to inherent shortcomings in cosine response and frequency response have been discussed and appropriate corrections have been applied. Preliminary results on turbulent spectra over a transpiring crop are presented. Further work employing sensors with better response characteristics is needed to substantiate our conclusions.

Acknowledgments. This study was conducted with support of the Atmospheric Sciences Section, National Science Foundation, under Grant ATM 75-100000 A01. Our thanks to Dr. Blaine Blad and Messrs. Dale E. Sandin, Thomas Keber and James Hines who assisted in the field observation and data computation, to Mrs. Roberta Sandhorst for stenographic work, to Mrs. Susan Cannon and Mr. Bruce Sandhorst for drafting, and to Dr. Albert Weiss and Mr. T. Grayson Redford, Jr., for their review of this paper. We wish to thank Dr. John Kennedy and Mr. Dale Harris for their help in calibration of propeller anemometers in the University of Iowa wind tunnel facility.

\section{REFERENCES}

Brakke, T. W., S. B. Verma and N. J. Rosenberg, 1978: Local and regional components of sensible heat advection. $J$. Appl. Meteor., 17, 955-963.

Haugen, D. A., J. C. Kaimal and E. F. Bradley, 1971: An experimental study of Reynolds stress and heat flux in the atmospheric surface layer. Quart. J. Roy. Meteor. Soc., 97, 168-180.

Horst, T. W., 1972: A computer algorithm for correcting noncosine response of the Gill anemometer. Pacific Northwest Laboratory 1971 Annual Report to the USAEC Div. of Biology and Medicine, Vol. II : Physical Science, Part I: Atmospheric Sciences, BNWL-1651-1, Battelle, Pacific Northwest Laboratories, Richland, WA.

- - 1973: Corrections for response errors in a three component propeller anemometer. J. Appl. Meteor., 12, 716-725.

Jenkins, G. M., and D. G. Watts, 1968: Spectral Analysis and Its Applications. Holden-Day, 252-255.

Kaimal, J. C., J. C. Wyngaard, Y. Izumi and O. R. Coté, 1972: Spectral characteristics of surface-layer turbulence. Quart.J. Roy. Meteor. Soc., 98, 563-589.

McBean, G. A., 1971: The variations of the statistics of wind, temperature and humidity fluctuations with stability. Bound.-Layer Meteor., 1, 438-457.

-- , and M. Miyake, 1972: Turbulent transfer mechanisms in the atmospheric surface layer. Quart. J. Roy. Meteor., Soc. 98, 383-398.

Miyake, M., and G. A. McBean, 1970: On the measurement of vertical transport over land. Bound.-Layer Meteor., 1, 88-101.

Motha, R. P., S. B. Verma and N. J. Rosenberg, 1979: Turbulence under conditions of sensible heat advection. J. Appl. Meteor., 18 (in press).

Pasquill, F., 1972: Some aspects of boundary layer description. Quart. J. Roy. Meteor. Soc., 98, 469-494.

Priestley, C. H. B., 1959: Turbulent Transfer in the Lower Atmosphere. The University of Chicago Press, $130 \mathrm{pp}$.

Silversides, R. H., 1974: On scaling parameters for turbulence spectra within plant canopies. Agric. Meteor., 13, 203-211.

Rosenberg, N. J., 1969: Seasonal patterns in evapotranspiration by irrigated alfalfa in the central Great Plains. Agron. J., 61, $879-886$.

- , and S. B. Verma, 1978: Extreme evapotranspiration by irrigated alfalfa: A consequence of the 1976 midwestern drought. J. Appl. Meteor., 17, 934-941.

Wyngaard, J. C., 1973: Workshop on Micrometeorology. Amer. Meteor. Soc. (see pp. 101-149). 